\title{
清浄鋼溶製技術
}

北川修三*, 中山 傑*, 新貝 元**

\section{Refining Technology for High Purity Steel}

\author{
Syuzo Kitagawa, Suguru Nakayama and Motoshi Shinkai
}

\begin{abstract}
Synopsis
Recently the refining technology for high purity steel has been studied over the world.

Secondary refining technologies to obtain less than $40 \mathrm{ppm}$ phosphorus and less than $30 \mathrm{ppm}$ nitrogen was investigated in our LF-RH process.

In order to produce low phosphorous steel, the combination of the tapping without killing, dephosphorization injection and deslagging in the ladle led to reduce phosphorus to less than $40 \mathrm{ppm}$ easily.

In the case of producing the low nitrogen steel, the degassing under less than 30 ppm sulfur content is effective in denitrogenigation because sulfur is adsorbed positively at surface phase and retard the chemical reaction $\left(2 \underline{\mathrm{N}} \rightarrow \mathrm{N}_{2}\right)$, then this degassing method makes it possible easily to reduce nitrogen to less than $30 \mathrm{ppm}$ in mass production.
\end{abstract}

\section{1. 緒}

\section{품}

近年, 鋼の潜在機能を引き出すべく，その清浄 化技術の改善が盛んに行われている。

鋼の不純物を低減させるためには二次精鍊技術 が重要な役割を果たしており，特にLF(Ladle Furnace)に代表される加熱機能を有する取鎝精 鍊は有効であり，その普及には著しいすのがある。 大同特殊鋼秼知多工場（以下当工場という）に おいても昭和 57 年に No.1 LF の導入, 昭和 60 年に No.2 LF の導入を図り，品質の向上・安定化さら には品質要求への対応に努めてきた。 今回, この LF と従来からある $\mathrm{RH}$ 脱がス装置

“大同特殊鋼侏生産本部知多工場

**大同特殊鋼(
を活用した二次精鍊ブロセスに括ける清浄化技術 の5ち脱 $[\mathrm{P}]$, 脱 $[\mathrm{N}]$ 技術について述べる。

\section{2. 精錬プロセスの概要}

母溶鋼は公称 70t 電気炉（実湯 85t）から供給さ れる。

当工場の二次精錬設備としては LF と RH 脱ガ ス装置であり，そのプロセスは Fig. 1 に示す通り である。

除涬ステーションには脱[P]Injection 装置を 有し, Injection 後の除㳯との組合せで効率的な脱 〔P]精錬を狙っている。また精鍊ステーションに はスラターーメタル界面下の比較的浅い位置にフラ ックスなどを吹き込むための脱[S]用 Shallow lnjection 装置を設けてある。なお， RH 脱ガスを 含めた各精鍊ポシション間は取鍋台車に上り容鋼 


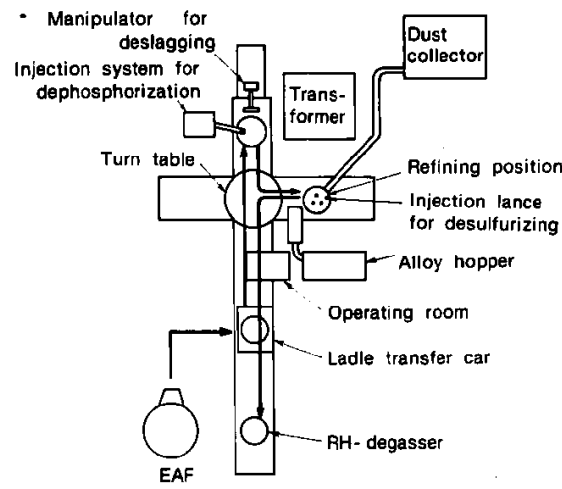

Fig. 1. Layout of LF at Chita plant.

移動するレイアウトとなっている。

\section{3. 低 $[P]$ 鋼溶製技術}

（1）従来の脱[P]法とその限界

電気炉製鋼法における脱〔P]法としては炉内酸 化精鍊におけるスラグ更新（ダブル・スラグ法） によるむのが一般的である。しかし電気炉はその 構造上十分なスラグーメタル擋捧が得られないた め，脱 $[\mathrm{P}] 反$ 応促進が十分でないこと，また脱 $[\mathrm{P}]$ 精鍊後の除涬が十分にできないため復[P]が生 し， Fig. 2 に示すように低い脱[P]率にとどまっ ている。

残涬による復[P]を防止するために（末脱酸出 鋼十リレードル) 法が举げられる。しかしリレー ドルによる温度降下補償のために電気炉は高温出 鋼を余儀なくされ $\mathrm{P}$ 分配比 $(\mathrm{P}) /[\mathrm{P}]$ は低下し，結 局脱[P]率が低下するという問題があった。

(2) 最適脱[P]法の検討

前述した観点から低[P]鋼㾂製にあたっては脱 [P]反応促進条件扰よび復[P]防止条件を满足す る精鍊プロセスが必要となる。

すなわち

(1)低温精錬 $((\mathrm{P}) /[\mathrm{P}]$ の向上 $) \rightarrow$ 出鋼後の鍋内処 理

(2)擋挥力強化 (脱[P]反応促進) $\rightarrow$ Injection 法, Bottom bubbling 法

(3) P 分配比の向上 $\rightarrow$ 最適フラックスの選定

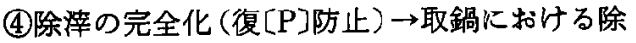
涬

を満足させるべく当工場では LF 還元精鍊前の除

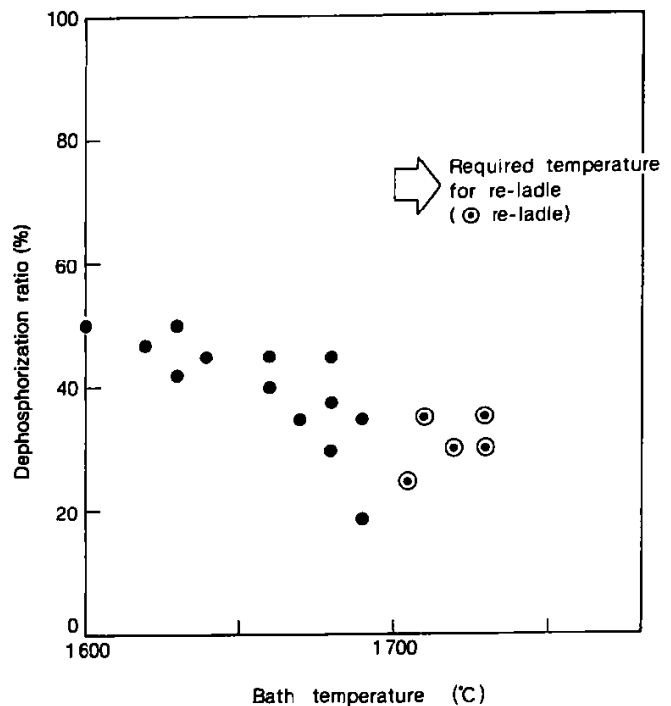

Fig. 2. Relation between bath temperature and dephosphorization ratio.

涬ステーションに脱[P]Injection を設置し, Injection 後の完全除涬之組合せた脱[P]プロセスを導 入した。また本プロセスの中で重要な位置をしめ るフラックス組成の梚討を行った。

(3) 脱[P]フラックスの検討

低[P]鋼溶製に拈いては，まずいかに効率上く 脱[P]するかがポイントであり，とりわけ最適 ラックスの選定が重要である。脱 $[\mathrm{P}]$ 用フラック スとしては，安定なりン酸塩を生成するてルカリ 金属・アルカリ土類金属の酸化物をその候補に挙 げることができる。Table 1 にこれら脱[P]フラ ックスの比較を示す。

当工場のように構造用低合金鋼を対象とする脱 [P]フラックスとしては, 総合評価としてやはり $\mathrm{Na}_{2} \mathrm{CO}_{3}$ 系拈よび $\mathrm{CaO}$ 系フラックスが実用的と

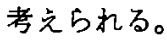

(4) フラックスによる脱[P]結果

前述したよらに脱[P]プロセスはFig. 3 に示す よ5に低温未脱酸出鋼, 脱[P]フラックス Injection，除涬，LF 昇熱・還元精錬から構成される。 末脱酸出鋼においては電気炉酸化涬も同時に取 鍋中に出涬し，その酸化洋か脱[P]Injection 時に 必要な酸素ボテンシャルを供給する源となってい る。

このプロセスに拈いて前述の $\mathrm{Na}_{2} \mathrm{CO}_{3}$ フラック スと $\mathrm{CaO}$ 系フラックス（涬化性向上として $\mathrm{CaF}_{2}$ 
Table 1. Comparison of flux for dephosphorization in low alloy steel.

\begin{tabular}{|c|c|c|c|}
\hline Flux & Advantage & Disadvantage & $\begin{array}{c}\text { Total } \\
\text { evaluation }\end{array}$ \\
\hline $\mathrm{Na}_{2} \mathrm{CO}_{3}$ & $\begin{array}{l}\text { - High ability of de-P } \\
\text { - Simultaneous removal } \\
\text { of } \mathrm{P} \text { and } \mathrm{S}\end{array}$ & $\begin{array}{l}\text { - Fume pollution } \\
\text { - Endothermic reaction } \\
\text { - Large evaporation } \\
\text { loss }\end{array}$ & 0 \\
\hline $\begin{array}{l}\mathrm{CaO}^{-} \\
\mathrm{CaF}_{2}\end{array}$ & $\begin{array}{l}\text { - Good ability of de-P } \\
\text { - Cheeper, less fume }\end{array}$ & $\begin{array}{l}\text { - Less removability of } \\
{[P] \text { and }[S] \text { simulta- }} \\
\text { neously than } \mathrm{Na}_{2} \mathrm{CO}_{3}\end{array}$ & $\mathrm{O}$ \\
\hline $\mathrm{CaCl}_{2}$ & - Good ability of de-P & $\begin{array}{l}\text { - Less effective "de-P" } \\
\text { for steel } \\
\text { - Hygroscopic flux }\end{array}$ & $x$ \\
\hline $\mathrm{BaO}$ & $\begin{array}{l}\text { - Good ability of de-P } \\
\text { for stainless steel }\end{array}$ & - Expensive & $x$ \\
\hline $\mathrm{CaC}_{2}$ & $\begin{array}{l}\text { - High ability of de-P } \\
\text { for stainless steel } \\
\text { - Reducing As, } \mathrm{Sn}, \mathrm{Sb}\end{array}$ & $\begin{array}{l}\text { - Carbon pick-up } \\
\text { - Formation of harmful } \\
\text { slag }\left(\mathrm{Ca}_{3} \mathrm{P}\right)\end{array}$ & $x$ \\
\hline
\end{tabular}

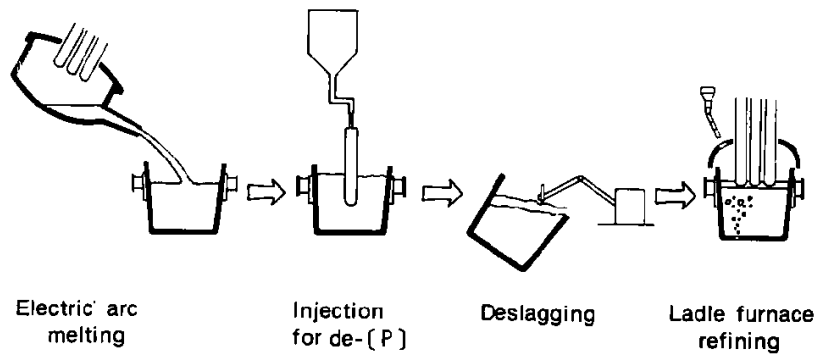

Fig. 3. Dephosphorizing process at Chita plant.

20\%混合)を用いて脱 $(P]$ 挙動を比較した。Fig. 4 にそれらの脱 $\left[\mathrm{P}\right.$ ]举動を示す。 $\mathrm{Na}_{2} \mathrm{CO}_{3}$ フラックス を用いた場合の方が $\mathrm{CaO}$ 采フラックスの場合よ りも脱[P]反応効率がすぐれている。

また, これらのデータ水渡らの式に従い比較 整理したものがFig.5である。

$\mathrm{Na}_{2} \mathrm{CO}_{3}$ の場合，水渡らの式に対して若干上方 に位置してはいるが, $\mathrm{Na}_{2} \mathrm{CO}_{3}, \mathrm{CaO}$ 共にほば同一 に整理される。つまり $\mathrm{Na}_{2} \mathrm{CO}_{3}$ を Injectionするこ とにより強塩基性の $\mathrm{Na}_{2} \mathrm{O}$ は $\mathrm{CaO}$ 上り1.2倍程 度の脱[P]能を有しており， $\mathrm{Na}_{2} \mathrm{O}$ として歩留れ ば CaO に対して優利であるといえる。

一方, Fig. 6 に $\mathrm{Na}_{2} \mathrm{CO}_{3}$ の場合の $\mathrm{P}$ 分配比々溶 鋼温度の関係を示す。脱 $[\mathrm{P}] 反$ 応が低温汪ど有利 であることは平衡論の示すところであるが，とり わけ $\mathrm{Na}_{2} \mathrm{CO}_{3}$ を使用する場合はその影響が顕著で

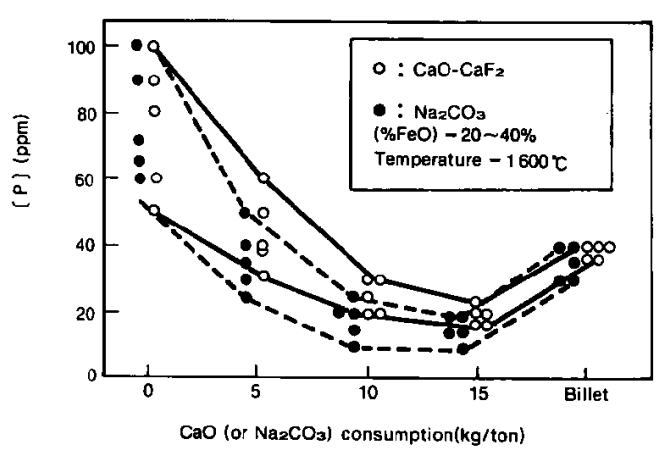

Fig. 4. Change of $[P]$ during injection for de- $[P]$.

ある。すなわち, 浴温が高くなるにつれ, Fig. 7に 示す上 $5 に \mathrm{Na}_{2} \mathrm{O}$ の蒸発口スが増加し有效原単 位を下げる結果となる。したがって $\mathrm{Na}_{2} \mathrm{CO}_{3}$ 系つ 


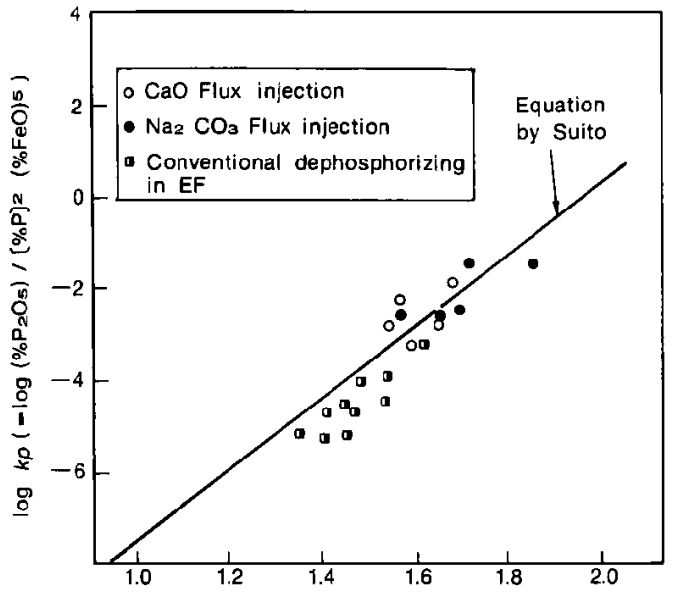

$\log \left((\% \mathrm{CaO})+\left(\% \mathrm{CaF}_{2}\right)+0.3(\% \mathrm{MgO})-0.5\left(\% \mathrm{P}_{2} \mathrm{O}_{5}\right)\right.$ $-0.05(\% \mathrm{FeO})+1.2(\% \mathrm{Na} 2 \mathrm{O}))$

Fig. 5. Relation between slag composition and $\mathrm{P}$ distribution ratio.

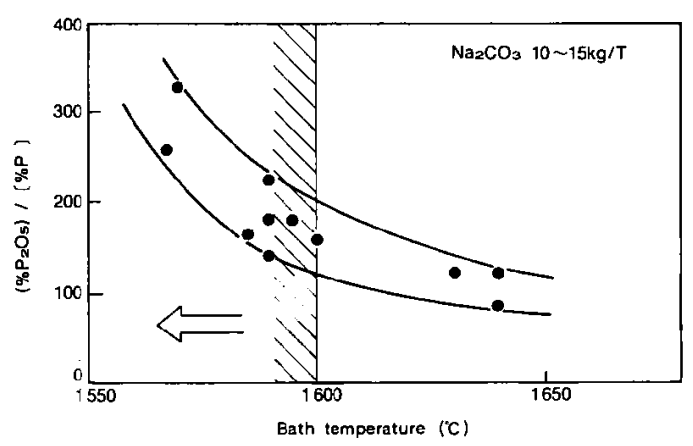

Fig. 6. Effect of bath temperature on phosphorous partition ratio.

ラックスによる脱 $[\mathrm{P}]$ の場合には $1600^{\circ} \mathrm{C}$ 以下の処 理温度にすることが望ましい。しかし溶鋼脱 [P] を $1600^{\circ} \mathrm{C}$ 以下の低温から始めることはその後の 昇熱負担の増加など実操業上好をしくない。をた $\mathrm{Na}_{2} \mathrm{CO}_{3}$ を使用する場合, 発煙拉よび耐火物溶損 の問題が生する。以上の観点から溶鋼脱[P]を実 操業で実施する場合には $\mathrm{CaO}$ 系フラックスの方 が好ましいと評価できる。

な技 Fig. 5 に脱 $[\mathrm{P}]$ Injection の評価として, 従 来の電気炉内脱 $[\mathrm{P}]$ 法では $\mathrm{P}$ 分配比は水渡らの 式(1)よりやや下に位置しているのに対して，取鍋 Injection 法では $\mathrm{Na}_{2} \mathrm{CO}_{3}, \mathrm{CaO}$ 禾フラックス共に バラッキはあるすのの注ほ水渡らの式にのってお り, Injection 法の効果が認められる。

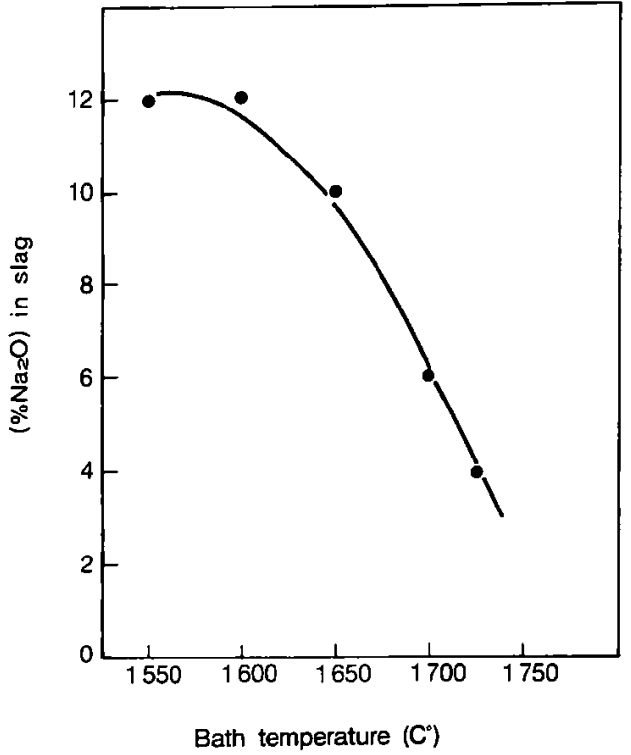

Fig. 7. Relation between bath temperature and $\left(\% \mathrm{Na}_{2} \mathrm{O}\right)$ in slag.

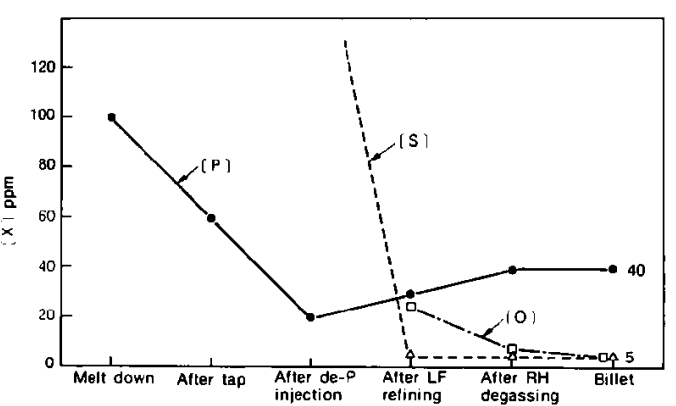

Fig. 8. Reduction of impurities during refining through ELVAC.

\section{（5）低 $[P]$ 鋼溶製結果}

以上の知見を踏をえた低 $[\mathrm{P}]$ 鋼溶製結果を Fig. 8 亿示す。脱 [P]後, LF, RH での強還元精鍊によ $\eta[\mathrm{S}],[\mathrm{O}]$ をングル ppm むで低減しても最終 製品[P]を 40ppm 以下に抑克ることが可能とな った。

Fig. 9 に脱 $[\mathrm{P}]$ 後から最終 $[\mathrm{P}]$ レベルまでの復 $[\mathrm{P}]$ 量を示す。合金からの復 $[\mathrm{P}]$ 以外の他に残留ス ラグ，耐火物中からの復 $[\mathrm{P}]$ が考えられる。低 $[\mathrm{P}]$ レベルに括ける脱 $[P]$ 技術は，復 $[\mathrm{P}]$ 抑制技術であ るとの観点に立ち，復 $[P]$ 源の解明，復 $[P] の$ 㧕制 を今後图って行く。 


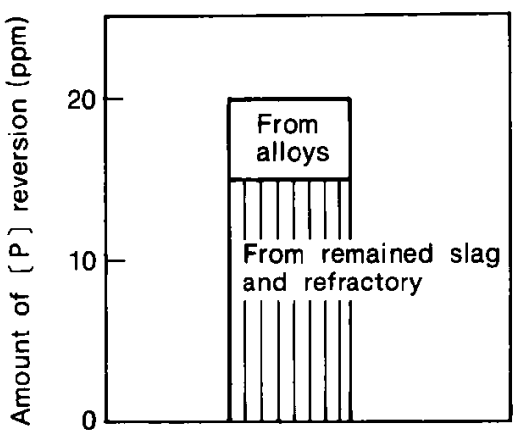

Fig. 9. Estimation of $[P]$ reversion.

\section{4. 低 $[\mathrm{N}]$ 鋼溶製技術}

（1）電気炉内脱 $[N]$ 挙動

電気炉内での脱[N]は Fig. 10 に示す通り脱炭 時の CO ガスによる脱 $[\mathrm{N}]$ 効果が大きい。

したがって電気炉内脱炭酸素吹精の強化と RH 脱ガスにより $[\mathrm{N}]<30 \mathrm{ppm}$ の溶製は可能である。

一方, 近年, 電気炉操業においては能率の向上, 電力原単位の低減を目的に溶解期に扣ける酸素富 化操業の適用が行われている。したがって Melt down 時に扰ける[C]值は低いレべルとなってお り炉内脱炭による脱 $[N]$ は期待できない。

そこで高能率・省エネルギー操業である酸素富 化操業を堅持しつつ低 $[\mathrm{N}]$ 化可能な脱 $[\mathrm{N}]$ 技術の 確立が必要である。な敃酸素富化操業下に括ける 炉中[N]は 50〜70ppm 上なっている。

（2）出鋼時の吸 [N]抑制

電気炉内で脱酸した溶鋼を出鋼すると出鋼流は

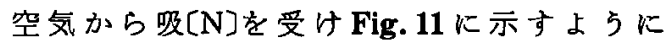
$30 \mathrm{ppm}$ 程度の[N]pick upがある。

この曼 [N]を防止すへく以下二通りの試験を実 施した。

(1) 取鍋内 $\mathrm{CaCO}_{3}$ 添加法

出鋼時取鍋内に $\mathrm{CaCO}_{3}$ を添加し(1)式の反応で 発生する $\mathrm{CO}_{2}$ ガスによる空気しゃ断を試みた。

$$
\mathrm{CaCO}_{3} \stackrel{\text { 分解 }}{\longrightarrow} \mathrm{CaO}+\mathrm{CO}_{2} \uparrow \quad \cdots \cdot . \cdot(1)
$$

その結果を同じくFig. 10 に示すが出鋼時の [N]pick upは抑えられており $\mathrm{CaCO}_{3}$ 添加による 空気しゃ断効果恃大きい。

(2) 末脱酸出鋼法

容鋼中の[O]を高めておけば容鋼の吸 $[N] は$ は防 止できその方法として未脱酸出鋼がある。未脱酸

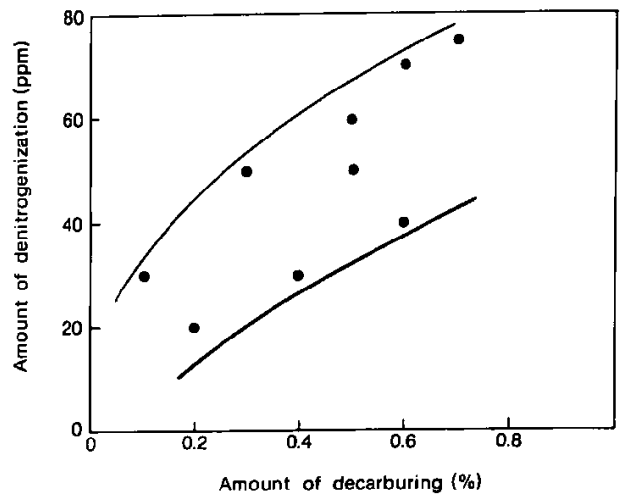

Fig. 10. Effect of decarburizing on denitrogenization.

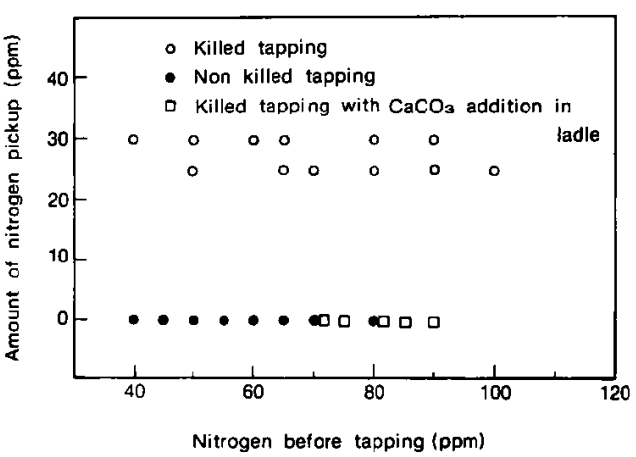

Fig. 11. Nitrogen pickup during tapping.

出鋼による吸 $[N]$ Fig. 11 K併記するが, 吸[N] は防止されている。

両法とあ吸[N]防止效果は大きいが， $\mathrm{CaCO}_{3}$ 添 加法の場合 $\mathrm{CaCO}_{3}$ 分解時の吸熱に上る溶鋼温度 の低下，また $\mathrm{CaCO}_{3}$ 添加時の火级発生大なと操業 上の問題がある。

一方，低 $[\mathrm{P}]$ 化のため末脱酸出鋼が必要なこと により現在当工場では出鋼時の吸 $[\mathrm{N}]$ 防止策とし ては末脱酸出鋼法を採用している。

(3) RH 脱がスに怙ける脱[N]挙動

$\mathrm{RH}$ 脱ガス中の脱 [N]挙動の数例を Fig. 12 に 示寸。N は他のガス成分とは異なりその脱 $[\mathrm{N}]$ 速 度は遅い。これは脱 $[\mathrm{N}] 反$ 反応が溶鋼自由表面に招 ける化学反応 $\left(2 \underline{\mathrm{N}} \rightarrow \mathrm{N}_{2}\right)$ 律速であるためといわ れている(2)。

溶鋼自由表面における化学反応を阻害するるの 


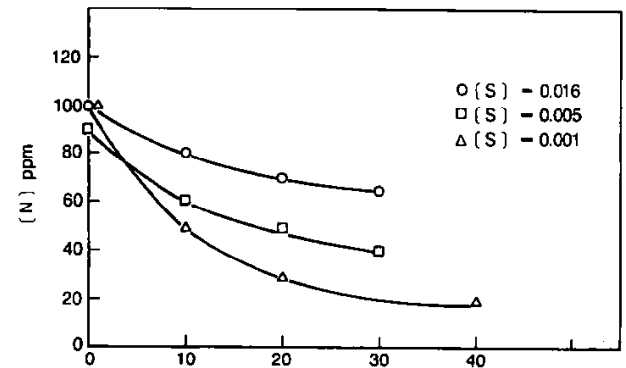

RH treatment time (min)

Fig. 12. Denitrogenization during $\mathrm{RH}$ degassing.

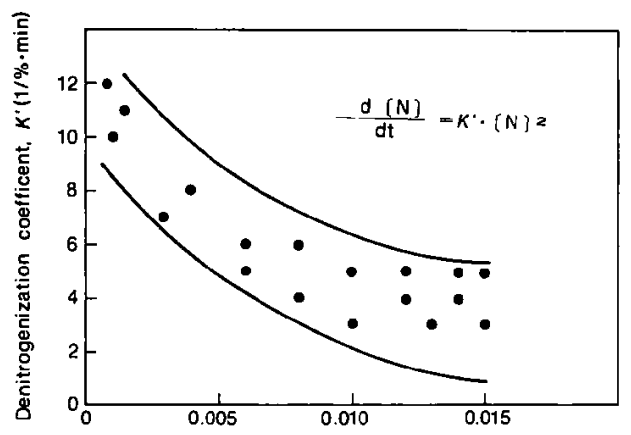

(S) $\%$

Fig. 13. Effect of sulfur in molten steel on denitrogenization coefficient.

としては表面活性元素の表面吸着がある。したが って[O], [S]等表面活性元素を極力低レベルにす ることが脱[N]反応促進には有利である。[O]に ついては LF， RH 精錬において 10ppm 程度であ ク大きな影響はないと考えられる。一方，[S]につ いては鋼材の用途に応して各種の規格が運用され ている。そこで脱 $[\mathrm{N}]$ 速度に及注す $[S]$ 含有量の影 響を調査した結果を Fig. 13 に示す。

〔S]含有量の低下にしたがい，特に[S]<0.005 \%において脱[N]反応容量係数の增加が顕著であ る。低 $[S]$ 含有量下での真空処理により脱 $[\mathrm{N}]$ 速度 の向上, 到達 $[\mathrm{N}]$ 值の低減が可能である。

（4）低 $[N]$ 鋼溶製結果

以上の知見をもとに低 $[\mathrm{N}]$ 鋼を溶製しその結果 をFig. 14 に示す。電気炉内脱炭吹精を行わなく

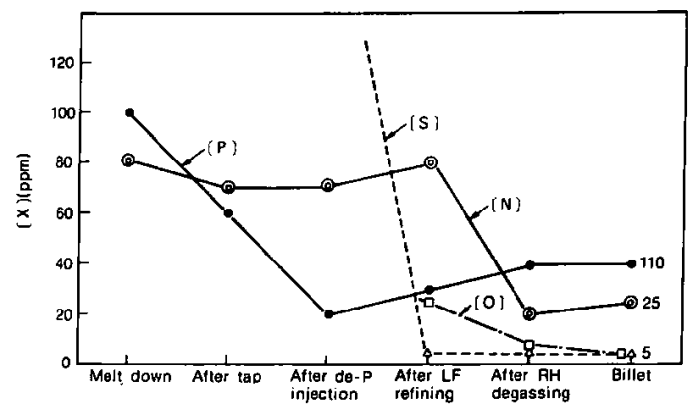

Fig. 14. Reduction of impurities during refining through ELVAC.

ても未脱酸出鋼, LFでの低[S]精鍊後の脱ガス処 理により容易に $[\mathrm{N}]<30 \mathrm{ppm}$ が溶製可能となっ た。今後の問題点としては LF 処理に和ける[N] pick upの抑制があり，LFのシール強化，合金， 副資材中の低 $[\mathrm{N}]$ 化が課題と考えている。

\section{5. ま と め \\ (1) 溶鋼脱 $[\mathrm{P}]$ 技術}

電炉末脱酸出鋼, $\mathrm{CaO}$ Injection お上び完全除 涬の組合せにより $[\mathrm{P}]<40 \mathrm{ppm}$ の大量溶製が可能 となった。

\section{(2) 脱[N]技術}

溶鋼表面活性元素である[S]含有量を低隇した 状態 $([S]<0.003 \%)$ での真空処理により $[N]<$ $30 \mathrm{ppm}$ が容易となった。

今回の脱 $[\mathrm{P}]$, 脱 $[\mathrm{N}]$ 技術と従来からの脱 $[\mathrm{O}]$ 技 術 $([O] 5 \mathrm{ppm})$, 脱 $[S]$ 技術 ([S] $5 \mathrm{ppm})$ と合 わせて $\mathrm{S}+\mathrm{P}+\mathrm{O}+\mathrm{N}<80 \mathrm{ppm}$ の技術の確立か 図れた。

今後は脱 $[\mathrm{P}]$ 技術に打いては復[P]防止技術之 して耐火物材質の低[P]化の検討を行5。 また脱 [N]技術においては電気厉，LF における 吸 [N]防止, さらには脱 $[\mathrm{N}]$ 速度向上として RH 多重ガス吹込みの検討を行って一層の不純物低減 技術を確立して行く。

$$
\text { （文献） }
$$

1）水渡英昭：鉄と鋼 70 (1984)， 366

2）成田，小山ら：鉄と鋼 57 (1971), 2207 